\title{
Gear Tooth Stress Measurements of Two Helicopter Planetary Stages
}

Timothy L. Krantz

Propulsion Directorate

U.S. Army Aviation Systems Command

Lewis Research Center

Cleveland, Ohio

Prepared for the

Sixth International Power Transmission and Gearing Conference sponsored by the American Society of Mechanical Engineers

Phoenix, Arizona, September 13-16, 1992 


\title{
GEAR TOOTH STRESS MEASUREMENTS OF TWO HELICOPTER PLANETARY STAGES
}

\author{
Timothy L. Krantz \\ Propulsion Directorate \\ U.S. Army Aviation Systems Command \\ Lewis Research Center \\ Cleveland, Ohio 44135
}

\begin{abstract}
Two versions of the planetary reduction stages from U.S. Army OH-58 helicopter main rotor transmissions were tested at the NASA Lewis Research Center. One sequential and one nonsequential planetary were tested. Sun gear and ring gear teeth strains were measured, and stresses were calculated from the strains. The alternating stress at the fillet of both the loaded and unloaded sides of the teeth and at the root of the sun gear teeth are reported. Typical stress variations as the gear tooth moves through the mesh are illustrated. At the tooth root location of the thin-rimmed sun gear, a significant stress was produced by a phenomenon other than the passing of a planet gear. The load variation among the planets was studied. Each planet produced its own distinctive load distribution on the ring and sun gears. The load variation was less for a three-planet, nonsequential design as compared to that of a four-planet, sequential design. The results reported enhance the data base for gear stress levels and provide data for the validation of analytical methods.
\end{abstract}

\section{INTRODUCTION}

Helicopter transmission designers continually seek to improve the life and decrease the weight of the transmission. To make these improvements, the designer must have a good understanding of the stress levels in the transmission components. Determining gear stress levels is especially difficult because of the complex geometry of the gear and because of the time-varying dynamic load imposed on the gear teeth. There have been many analytical and experimental studies on the stresses and strains in parallel axis gearing but not as many done on planetary gearing (Ma and Botman, 1984; Botman, 1976; Choy et al., 1988; Frater et al., 1983). This study was done to enhance the data base for gear stress levels in a planetary gear stage and to provide data for the validation of analytical codes.

Dynamic loads and gear stresses of any gearbox are complex phenomena. These phenomena in a planetary system are further complicated because the power is transmitted through parallel paths. The parallel power paths raise questions as to how planet-to-planet load sharing, planet phasing, and planet indexing affect the system dynamics and the resulting dynamic gear teeth loads and stresses. Botman (1980) reported on the results of experiments to study the vibration of a turboprop gearbox that included two planetary reduction stages. From the test results, he concluded that (1) there were significant variations in gear mesh loads for the different planets and (2) the casing vibration level depended on the speed, the torque, and whether the engine was accelerating or decelerating. Hayashi, et al. (1986) developed a special experimental technique to measure dynamic load sharing in planetary gears. By measuring the loads on the post that supported the planet gears, they studied planet-to-planet load sharing. They demonstrated that the dynamic load-sharing condition is considerably different from the static condition. Toda and Botman (1979) concluded that proper planet indexing has a drastic effect on the overall vibration of a gearbox with a planetary stage. However, the experimental hardware of this study was not indexed or matched for minimum vibration and optimal load sharing. Oswald (1987) conducted experimental stress tests on a $2240-\mathrm{kW}$ (3000-hp-) class helicopter transmission. He measured dynamic stress levels on spiral bevel and planetary gears using strain gages on the gear teeth roots and fillets.

The present study further investigated dynamic loads and load sharing in a planetary gear system. Experiments were conducted on two planetary stages from helicopter main rotor transmissions. Sun and ring gear teeth were instrumented with strain gages. The results of the experiments to measure dynamic gear tooth stresses are discussed.

\section{EXPERIMENTAL APPARATUS AND PROCEDURE}

\section{Test Hardware}

The two planetary stage designs studied are used in two versions of the Army's OH-58 helicopter main rotor transmission. The transmission has a reduction ratio of 17.44 overall, with the planetary stage contributing a ratio of 4.67 . The two planetaries are described in Table 1. The test hardware (Fig. 1) consisted of the sun, ring, and planet gears and planet bearings from the tousrnission. The carriers used during testing are similar in design to the flight hardware but are specially made for the test rig.

One of the planetary designs studied is the four planet (Fig. 1(a)). The planet gears are straddle mounted, supported on cylindrical roller bearings. The ring gear is spline mounted into the housing, which provides a fairly rigid mount in the radial directions. The sun gear, a very thin-rimmed gear, is mounted such that it is relatively free to 
TABLE 1.-PLANETARY HARDWARE DATA

[Planetary reduction ratio, 4.667.]

\begin{tabular}{|l|c|c|c|c|c|c|}
\hline Gear & $\begin{array}{c}\text { Number } \\
\text { of } \\
\text { teeth }\end{array}$ & $\begin{array}{c}\text { Module, } \\
\text { mm }\end{array}$ & $\begin{array}{c}\text { Diametral } \\
\text { pitch, } \\
\text { in. }^{-1}\end{array}$ & $\begin{array}{c}\text { Pressure } \\
\text { angle, } \\
\text { deg }\end{array}$ & \multicolumn{2}{|c|}{ Pitch diameter } \\
\cline { 6 - 8 } & 27 & 2.868 & 8.857 & 24.6 & 77.4 & 3.048 \\
\hline Sun & 35 & 2.868 & 8.857 & 24.6 & 100.4 & 3.048 \\
Planet & 99 & 2.778 & 9.143 & 20.2 & 275.0 & 10.828 \\
Ring & 99 & &
\end{tabular}

(b) Bearing data

\begin{tabular}{|l|c|c|c|c|c|c|c|c|}
\hline \multirow{2}{*}{ Jesign } & Type & \multicolumn{2}{|c|}{$\begin{array}{c}\text { Inside } \\
\text { diameter }\end{array}$} & \multicolumn{2}{|c|}{$\begin{array}{c}\text { Outside } \\
\text { diameter }\end{array}$} & \multicolumn{2}{|c|}{$\begin{array}{c}\text { Roller } \\
\text { diameter }\end{array}$} & \multirow{2}{*}{$\begin{array}{c}\text { Number } \\
\text { of } \\
\text { rollers } \\
\text { per row }\end{array}$} \\
\cline { 3 - 8 } & & $\mathrm{mm}$ & in. & $\mathrm{mm}$ & in. & $\mathrm{mm}$ & in. & 12 \\
\hline $\begin{array}{l}\text { Three- } \\
\text { planet }\end{array}$ & $\begin{array}{c}\text { Double row } \\
\text { spherical }\end{array}$ & 31.8 & 1.25 & 76.2 & 3.00 & 13 & 0.512 & 12 \\
\hline $\begin{array}{l}\text { Four- } \\
\text { planet }\end{array}$ & Cylindrical & 46.5 & 1.83 & 68.5 & 2.70 & 11 & 0.433 & 13 \\
\hline
\end{tabular}

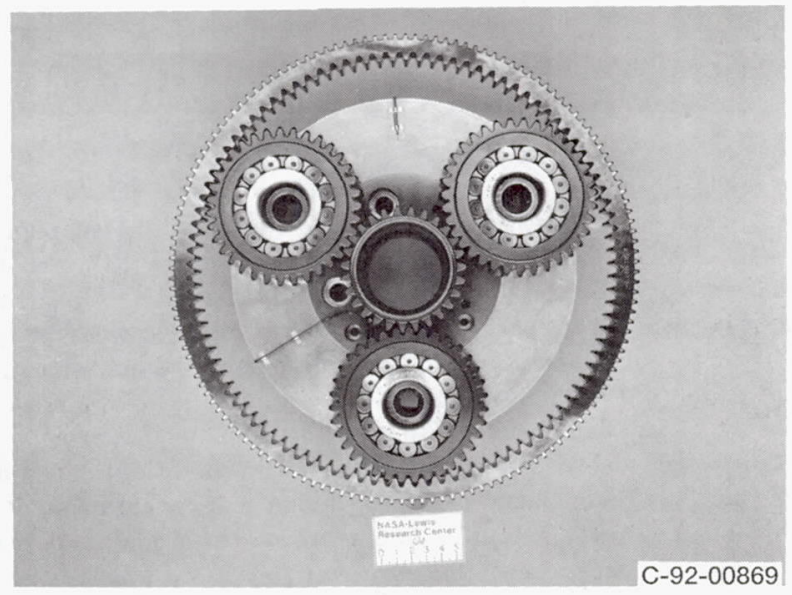

(a) Sun gear, planet gears, and carrier of three-planet design.

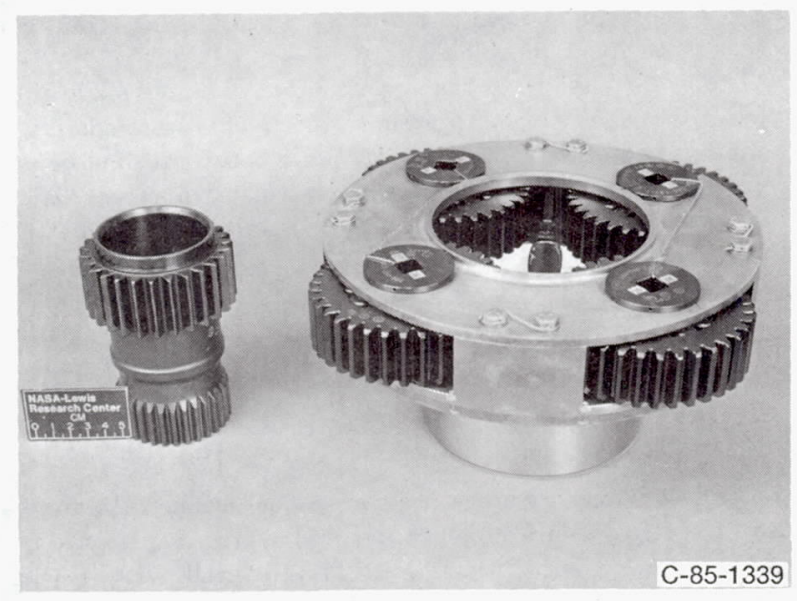

(b) Sun gear, planet gears, and carrier of four-planet design.

Fiqure 1.-Test hardware.

move radially. This planetary is a sequential design, meaning that at any instant each planet is operating at a different point along the line of action. Therefore, the sudden changes in gear mesh stiffnesses occur at a different instant of time for each planet in a particular sequential pattern.

The second planetary design studied is the three planet (Fig. 1(b)). The sun gear and ring gear are the same gears tested with the four-planet design. The planet gears are cantilever mounted from the carrier. This arrangement is less stiff laterally than the straddle mount of the four-planet design. To prevent angular misalignment between the planet gears and the sun and ring gears, the planet gears are supported on double-row spherical bearings. The three-planet design is a nonsequential one, meaning that at any instant each planet is nominally operating at the same point along the line of action.

\section{Test Rig and Instrumentation}

The test rig (Fig. 2) used is a regenerative torque, back-to-back configuration where a test and a slave section are loaded against each other by hydraulic pressure applied to a rotating torque actuator. The torque actuator twists the slave section sun gear relative to the highspeed shaft and thereby generates a torque into the closed-loop geartrain. An electric drive motor rotates the high-speed shaft and supplies the power to overcome frictional losses.

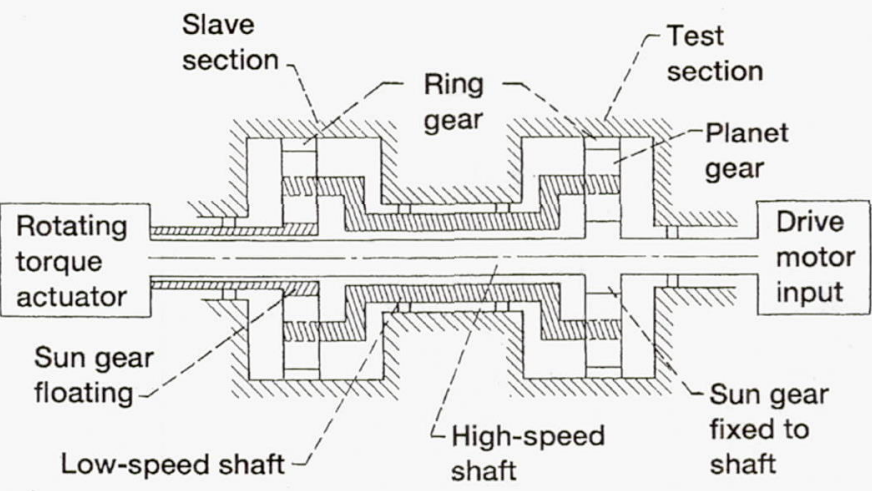

Figure 2.-Test facility.

The test and slave sections were lubricated by separate, identical systems that dispersed heated lubricant through a total of 16 lubrication jets per section. The lubricant used was a turbine engine oil that conforms to the DOD-L-85734 specification. The total lubricant flow rate to each section was $190 \mathrm{~cm}^{3} / \mathrm{sec}(3 \mathrm{gal} / \mathrm{min})$.

The power carried by the test section sun gear was determined by measuring the speed and torque of the shafts splined to the gear. The output signals from the torque measuring devices were low-pass filtered to remove frequencies above $0.2 \mathrm{~Hz}$ in the torque signals.

Tooth strains were measured using constantan strain gages having an active gage length of $0.38 \mathrm{~mm}(0.015 \mathrm{in}$.) and grid width of $0.51 \mathrm{~mm}(0.020 \mathrm{in}$.$) . On the sun gear, gages were placed at both the$ teeth fillets and teeth roots. On the ring gear, gages were placed only on the fillets. The sun fillet gages were located $50^{\circ}$ from the bottom of the root (Fig. 3), which for this gear is approximately equal to the classical $30^{\circ}$ tangency location of maximum stress as recommended by Cornell (1981). The sun root gage was located as near as possible to the bottom of the tooth root, but the actual mounted location was a few degrees from the bottom toward the driving side of the tooth. The ring fillet gages were located $30^{\circ}$ from the bottom of the root (rather than at the location of maximum stress nearer the tip) to provide safe clearance with the planet gear teeth. All gages were located at the center of the face width of the tooth.

Constant-voltage conditioning circuits were used for the gear tooth gages. The sun gear gages were connected to the circuit through slip rings. Once per revolution signals from both the sun gear and the carrier were recorded with the strain signals and analyzed to determine which planet gear was engaging an instrumented gear tooth. The gear teeth gages were calibrated by shunt calibration of both the active and dummy gages with the rig at its steady-state operating temperature. 

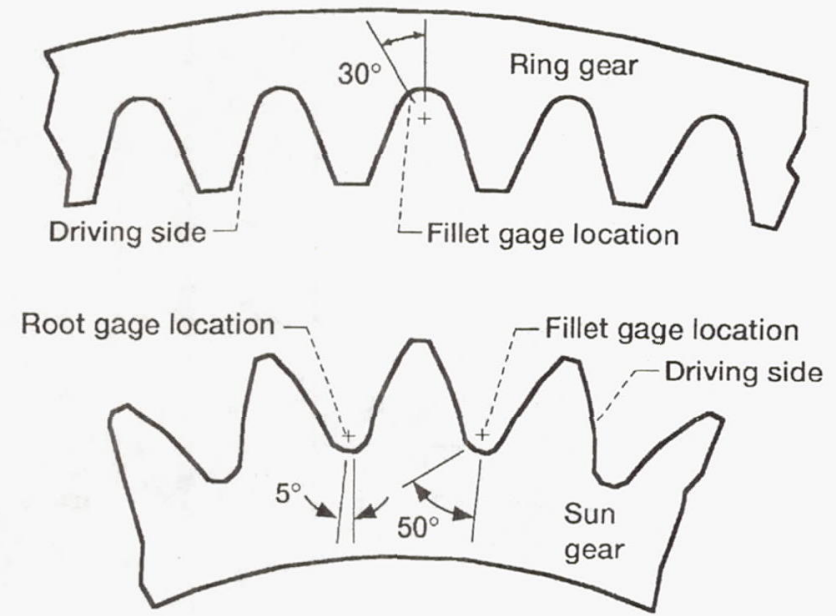

Figure 3.-Strain gage locations.

\section{$\underline{\text { Test Procedure and Data Processing }}$}

All tests were done with the lubricant entering the rig at a temperature of $80^{\circ} \mathrm{C}\left(180^{\circ} \mathrm{F}\right)$. At this temperature, the lubricant viscosity is $7.6 \mathrm{cS}\left(0.012 \mathrm{in.}^{2} / \mathrm{sec}\right)$. For each condition tested, the torque and speed of the test section sun gear were adjusted to the desired test condition. The rig was operated at this condition long enough for the bearing temperatures to stabilize before any data were recorded. For each test condition, at least $40 \mathrm{sec}$ of data were recorded on analog tape. The full speed test condition was $1620 \mathrm{rpm}$ for the sun gear. The maximum sun gear torque for the four-planet design was $1846 \mathrm{~N}$-m (16 $340 \mathrm{in.-lbf),} \mathrm{and} \mathrm{for} \mathrm{the} \mathrm{three-planet} \mathrm{design}$ was $1385 \mathrm{~N}-\mathrm{m}$ (12 $255 \mathrm{in}$-lbf). At the maximum power condition for both designs, each planet transferred $78 \mathrm{~kW}$ (105 hp) of power. This power level is somewhat greater than the continuous power rating of the transmission. Gear tooth strains were first measured on the loaded side of the teeth by applying torque and rotating the test section sun gear in the clockwise direction. A second set of tests was then done with both the torque and direction of rotation reversed to measure strains on the unloaded sides of the teeth.

The analog tapes were played back through analog to digital converters, and the data were stored and processed digitally. The data were sampled at $10 \mathrm{kHz}$ with anti-aliasing filters set at $4 \mathrm{kHz}$. The data were digitally filtered to remove slip ring and other electrical noise from the strain gage signals. To convert from units of strain to units of stress, I assumed a biaxial state of stress and multiplied by the elastic modulus, $0.21 \times 10^{6} \mathrm{MPa}\left(30 \times 10^{6} \mathrm{psi}\right)$. Because the hydraulic loading device used to set the torque load on the sun gear could not be adjusted precisely, the tests were not done at exactly the desired torque value. The data were scaled by multiplying by the desired nominal torque and then dividing by the actual tested torque. The ratio of nominal torque to actual tested torque was typically 0.98 to 1.02 . The digital filters used on the data were applied with a phase compensation technique to preserve the phase relationship between the once per revolution signals and the strain data.

The constant-voltage strain gage signal conditioners were balanced at the start of the set of tests each day. The balancing was done after the rig had reached operating temperature and with no load applied to the gears. The balance potentiometers were not changed from this initial setting for the tests done that day. The strain gage data were analyzed to determine if the circuit balance drifted during the day's testing. Figure 4 shows how the mean stress calculated from fillet gage data varied for nine tests all done at the same nominal torque but at different speeds. The variation of the ring gear fillet mean stress was negligible, 3.5 MPa (500 psi), as

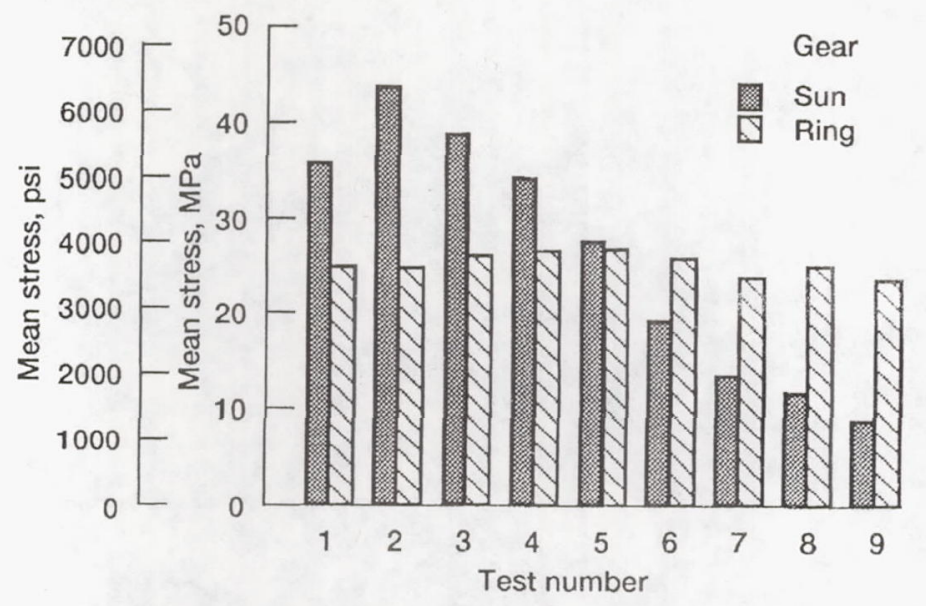

Figure 4.-Fillet gage mean stress at constant torque.

compared to the alternating stress, $414 \mathrm{MPa}$ (60 $000 \mathrm{psi})$. However, the variation in sun gear fillet mean stress was significant, $27.6 \mathrm{MPa}$ (4000 psi). The variation in the mean of the sun gear fillet data is likely because of the slight resistance changes of the slip ring. This variation in the mean was removed from the data by calculating a linear least-squares fit through the data for a particular test condition and then subtracting both the mean and the drift from the data. Therefore, the stresses reported are alternating stresses about a mathematically calculated zero mean and are not absolute stresses. Since the circuit balance of sun gear gages was affected by the slip ring condition, the absolute stresses in the sun gear cannot be accurately estimated. For the ring gear data, the mean subtracted from the data ranged from 27.6 to $7.17 \mathrm{MPa}$ (4000 to $1040 \mathrm{psi}$ ) for the loaded side of the tooth and ranged from 20.8 to $-16.1 \mathrm{MPa}$ (3020 to $-2330 \mathrm{psi}$ ) for the unloaded side of the tooth.

Once the time domain data were stored and processed digitally, the data were studied in the frequency domain. The power spectral density of the data was calculated using a 13 th-order transform, a Hanning window, and 20 -percent overlap. The spectral scaling was done with bandwidth corrections and was adjusted for window attenuation. The spectral amplitude was calculated in units of power per Hertz.

\section{RESULTS}

\section{Typical Stress Cycles}

Typical measured cycles of alternating stresses are illustrated in Figs. 5 to 7 for the four-planet design at the full-power test condition. The stresses in these figures are alternating stresses about a mathematically calculated zero mean and are not absolute values. The data from the three-planet design were similar and are not illustrated.

The ring gear fillet stresses are illustrated in Fig. 5. On the loaded side of the tooth, a sudden increase in tension occurs as the planet gear loads the instrumented tooth. Then follows a sudden change to compression as the tooth is unloaded and the neighboring tooth is engaged. For the unloaded side of the tooth, as the tooth is loaded there is a sudden increase in compression. The loading of a neighboring tooth does not cause a significant stress on the unloaded. side of the tooth. The amplitude of the alternating stress for a planet pass is approximately $410 \mathrm{MPa}(60000 \mathrm{psi})$ on the loaded side and approximately $690 \mathrm{MPa}(100000 \mathrm{psi})$ on the unloaded side of the tooth. The frequency contents of the two stress waves from the loaded and unloaded sides are very similar, being dominated by the planet pass frequency of $23 \mathrm{~Hz}$ and integer multiples of that frequency. 

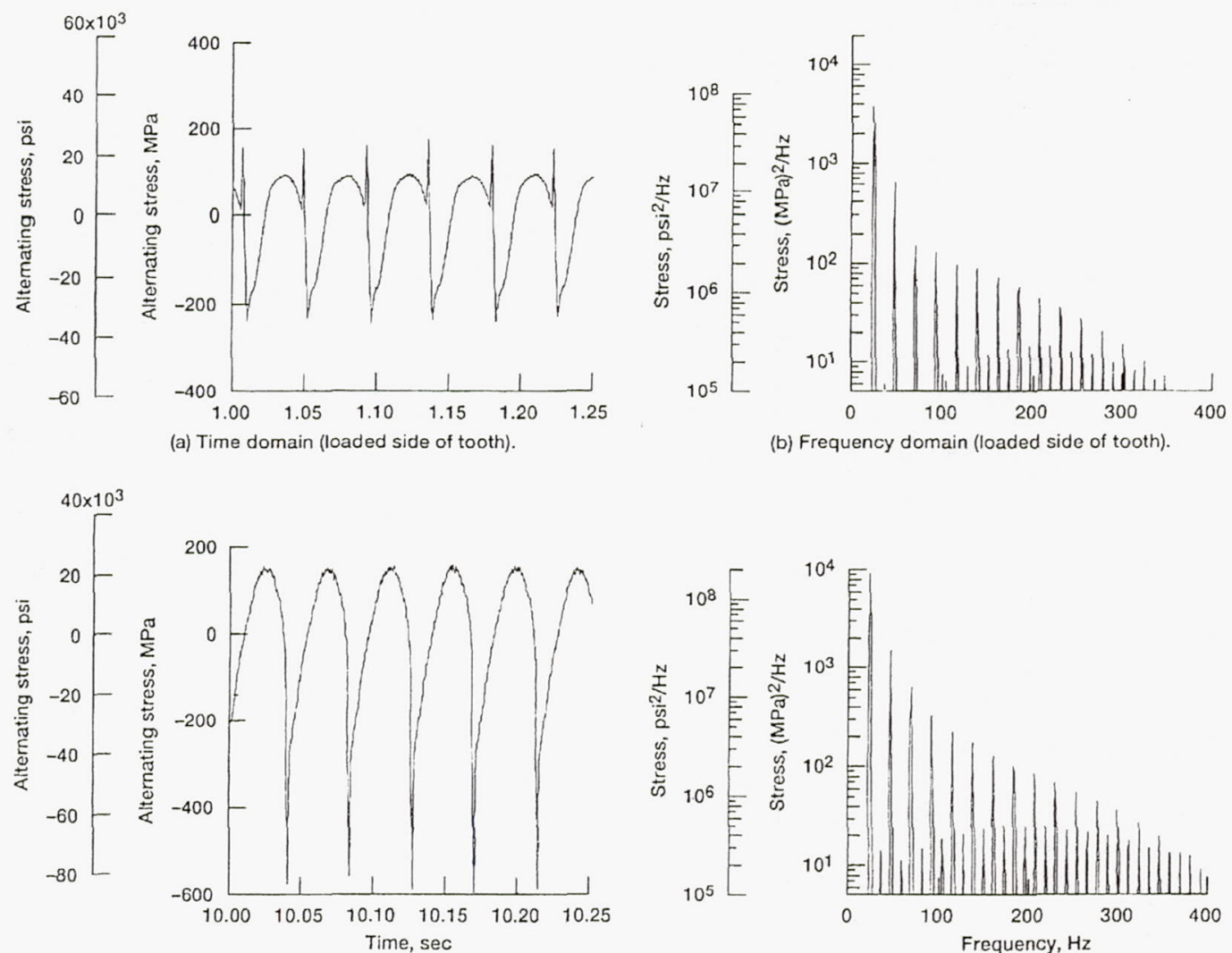

(c) Time domain (unloaded side of tooth).

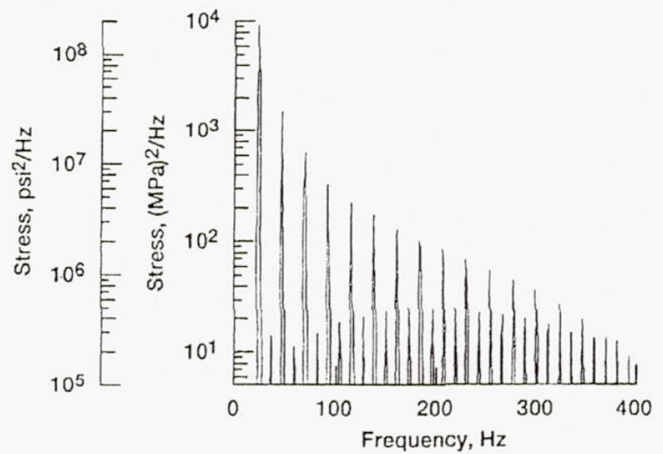

(d) Frequency domain (unloaded side of tooth).

Figure 5.-Typical stress data for ring gear fillet.
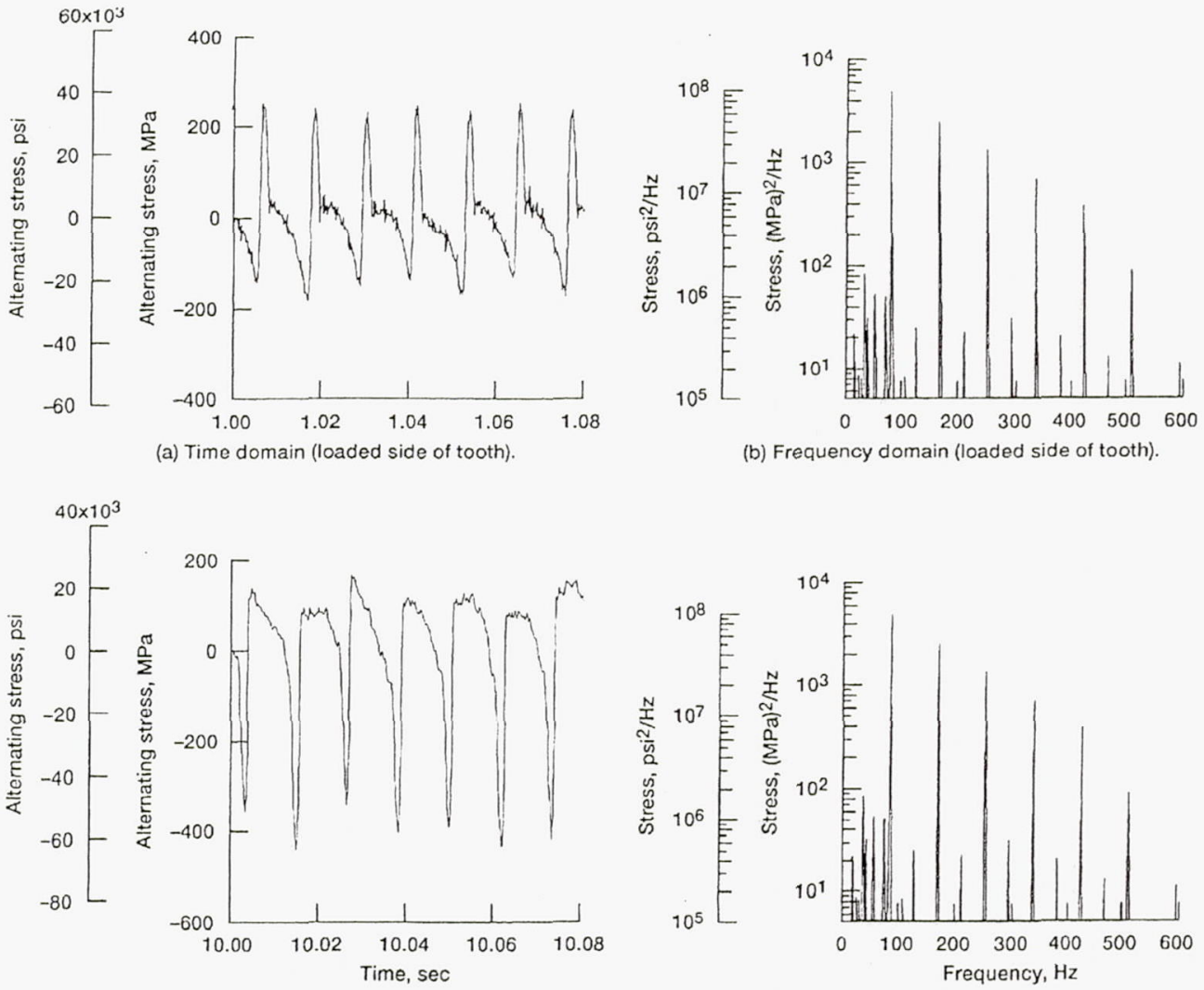

(c) Time domain (unloaded side of tooth).

(d) Frequency domain (unloaded side of tooth).

Figure 6.-Typical stress data for sun gear fillet. 


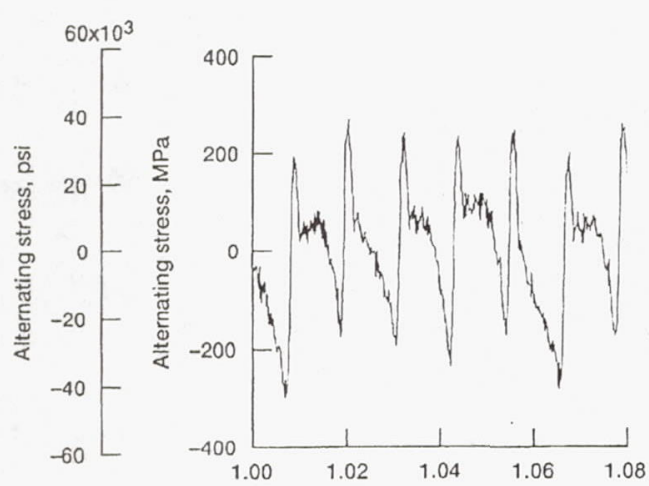

(a) Time domain (loaded side of tooth).

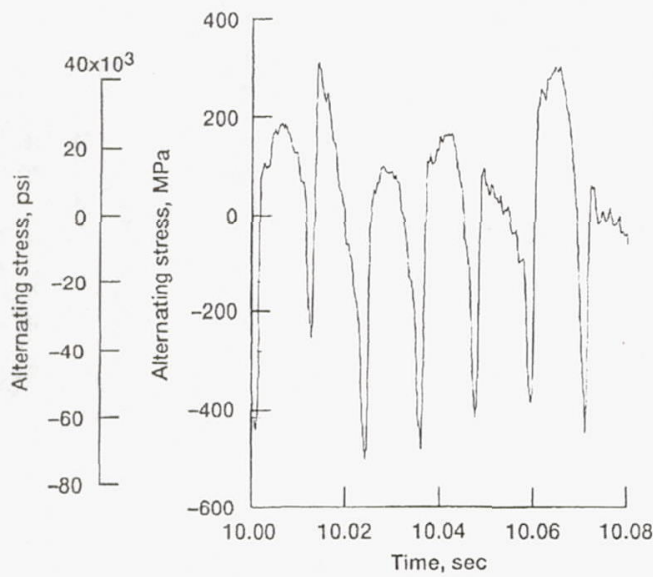

(c) Time domain (unloaded side of tooth).

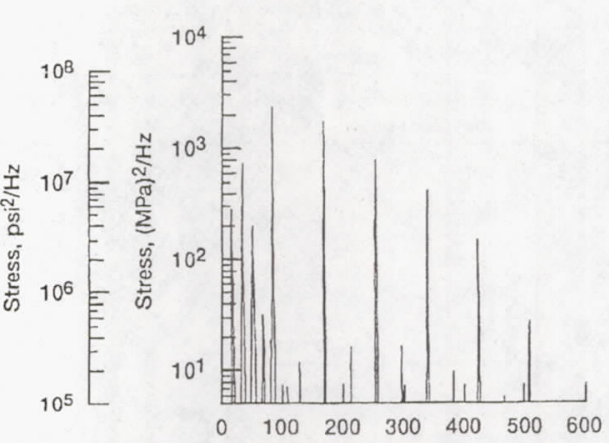

(b) Frequency domain (loaded side of tooth).

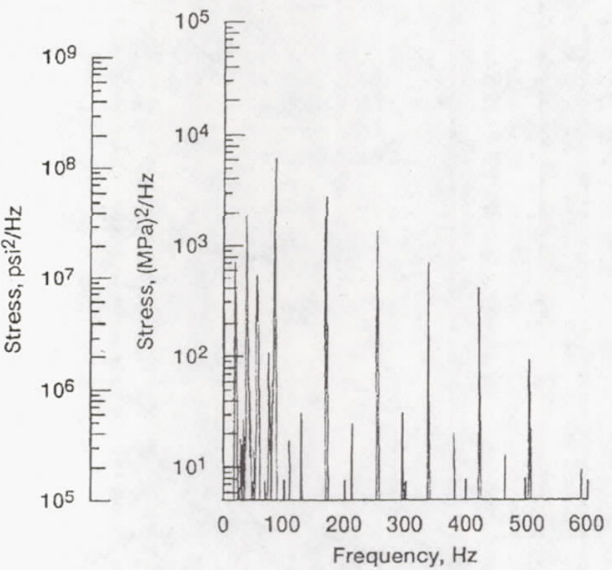

(d) Frequency domain (unloaded side of tooth).

Fiqure 7.-Typical stress data for sun gear root.

The sun gear fillet stresses are illustrated in Fig. 6. The stress variation on the loaded side of the tooth is characterized by a sudden increase in compression when its neighboring tooth is engaged, followed by a sudden change to tension when the tooth is engaged. The amplitude of the alternating stress on the loaded side is approximately $380 \mathrm{MPa}$ (55 $000 \mathrm{psi}$ ) and on the unloaded side is approximately $620 \mathrm{MPa}(90000 \mathrm{psi})$. The frequency content of the two stress waves is similar in that they are dominated by the planet passing frequency of $84.7 \mathrm{~Hz}$ and its integer multiples. There is also some significant energy in the frequencies below the planet passing frequency.

The sun gear root stresses are illustrated in Fig. 7. Because the gage was not placed exactly in the center of the root, the gage is still noted as being on the loaded or unloaded side of the tooth. Compared to the fillet location, the amplitude of the alternating stress for one planet pass is larger for the root location. The rim thickness has been established as an important parameter that affects the location of maximum stress in thin-rimmed gears (Bibel et al., 1991; Drago and Lutthens, 1983). For the root location, the amplitude of the alternating stress for one planet pass is about $450 \mathrm{MPa}(65000 \mathrm{psi}$ ) on the loaded side of the tooth and $690 \mathrm{MPa}(100000 \mathrm{psi})$ on the unloaded side. The stress cycles at the root location have characteristics similar to the cycles at the fillet location, but the data are more complex and seem, from the time domain plots, to be less regular.

The frequency domain plots (Figs. 6 and 7 ) illustrate that the frequency content of the stresses at the root and fillet locations is similar. However, the energy in the low frequencies is much more significant at the root compared to the fillet. These lower frequencies are equally spaced with respect to each other and are not sub- harmonics of the $84.7-\mathrm{Hz}$ planet pass frequency. The spacing between these frequencies depended on both the operating speed and the sun gear direction of rotation. This phenomenon is likely caused by a traveling stress wave in the thin-rimmed sun gear (Stockton, 1985), a shaft lateral resonance, or a similar activity. The spacing of these frequencies in the frequency domain for one test condition is illustrated in Fig. 8. Further investigation of this phenomenon is beyond the scope of this report.

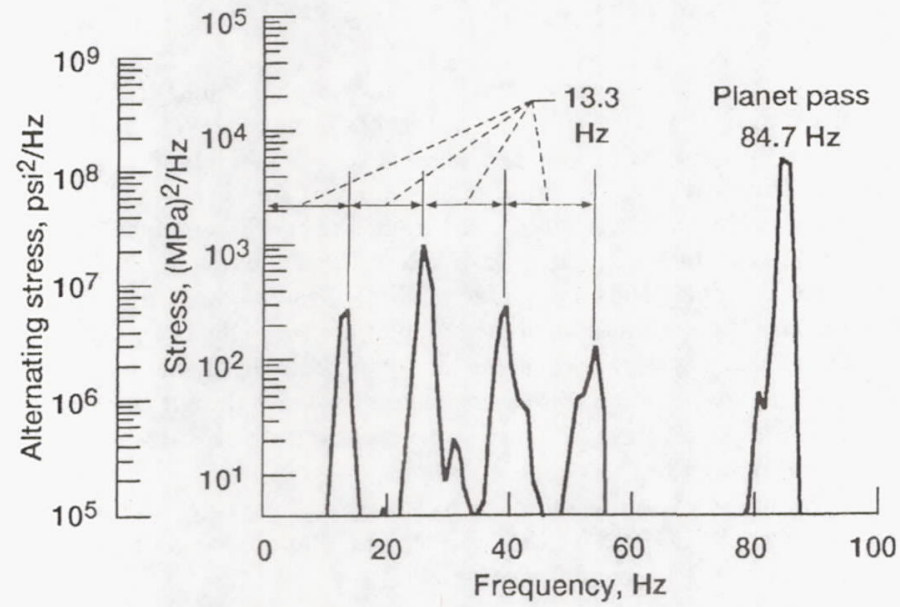

Figure 8.-Sun gear root stress on unloaded side of tooth at full power. 
TABLE 2.-PLANET GEAR AlTERNATING STRESS AT PULL, TESTED P'OWLK

\begin{tabular}{|c|c|c|c|c|c|c|c|c|c|c|c|c|c|}
\hline \multicolumn{2}{|c|}{ I'lanet } & \multicolumn{4}{|c|}{ Ring gear fillet } & \multicolumn{4}{|c|}{ Sun gear fillet } & \multicolumn{4}{|c|}{ Sun gear root } \\
\hline Design & Number & $\begin{array}{c}\text { Mean, } \\
\text { Ml'a }\end{array}$ & $\begin{array}{l}\text { Standard } \\
\text { deviation }\end{array}$ & $\begin{array}{c}\text { Mean, } \\
\text { psi }\end{array}$ & $\begin{array}{l}\text { Standard } \\
\text { deviation }\end{array}$ & $\begin{array}{l}\text { Mean, } \\
\text { MP'a }\end{array}$ & $\begin{array}{l}\text { Slandard } \\
\text { deviation }\end{array}$ & $\begin{array}{c}\text { Mean, } \\
\text { psi }\end{array}$ & $\begin{array}{l}\text { Standard } \\
\text { deviation }\end{array}$ & $\begin{array}{l}\text { Mean, } \\
\text { MPa }\end{array}$ & $\begin{array}{l}\text { Standard } \\
\text { deviation }\end{array}$ & $\begin{array}{c}\text { Mean, } \\
\text { psi }\end{array}$ & $\begin{array}{l}\text { Standard } \\
\text { deviation }\end{array}$ \\
\hline \multicolumn{14}{|c|}{ Loaded side of tooth } \\
\hline \multirow{5}{*}{$\begin{array}{l}\text { Four- } \\
\text { planet }\end{array}$} & 1 & 404 & 6.00 & $58.7 \times 10^{3}$ & 870 & 385 & 14.7 & $55.8 \times 10^{3}$ & 2130) & 438 & 26.7 & $63.6 \times 10^{3}$ & 3880 \\
\hline & 2 & 405 & 9.72 & 58.8 & 1410 & 370 & 16.9 & 53.7 & 2450 & 422 & 28.7 & 61.2 & 4160 \\
\hline & 3 & 408 & 2.81 & 59.2 & 1020 & 390 & 15.4 & 56.6 & 2240 & 411 & 28.0 & 64.0 & 4060 \\
\hline & 4 & 396 & 7.24 & 57.4 & 1050 & 375 & 16.1 & 54.4 & 2380 & 424 & 27.8 & 61.6 & 4040 \\
\hline & All & 103 & 8.89 & 58.5 & 1290 & 380 & 17.8 & 55.1 & 2580 & 431 & 29.1 & 62.6 & 4220 \\
\hline \multirow{4}{*}{$\begin{array}{l}\text { Three- } \\
\text { planct }\end{array}$} & 1 & 367 & 7.65 & $53.3 \times 10^{3}$ & 1110 & 396 & 11.3 & $57.5 \times 10^{3}$ & 2070 & 450 & 29.6 & $65.3 \times 10^{3}$ & 4290 \\
\hline & 2 & 376 & 5.03 & 54.6 & 730 & 393 & 12.5 & 57.0 & 1810 & 138 & 31.4 & 63.6 & 4550 \\
\hline & 2 & 367 & 6.34 & 53.3 & 920 & 409 & 12.2 & 59.3 & 1770 & 433 & 31.4 & 62.8 & 4550 \\
\hline & All & 371 & 7.65 & 53.8 & 1110 & 399 & 14.7 & 57.9 & 21411 & 110 & 31.6 & 63.9 & 4590 \\
\hline \multicolumn{14}{|c|}{ Unloaded side of tooth } \\
\hline \multirow{5}{*}{$\begin{array}{l}\text { Four- } \\
\text { planct }\end{array}$} & 1 & 767 & 8.96 & $111.3 \times 10^{3}$ & 1300 & 618 & 24.8 & $89.7 \times 10^{3}$ & 3600 & 673 & 53.1 & $97.6 \times 10^{3}$ & 7700 \\
\hline & 2 & 832 & 11.0 & 120.7 & 1600 & 596 & 28.9 & 86.5 & 4200 & 651 & 60.6 & 94.5 & 8800 \\
\hline & 3 & 739 & 8.96 & 107.2 & 1300 & 632 & 25.4 & 91.7 & 3700 & 691 & 51.4 & 100.3 & 7900 \\
\hline & 4 & 735 & 11.7 & 106.7 & 1700 & 608 & 29.6 & 88.2 & 4300 & 660 & 60.6 & 95.8 & 8800 \\
\hline & All & 751 & 15.2 & 109.0 & 2200 & 613 & 28.9 & 89.0 & 1200 & 669 & 58.5 & 97.1 & 8500 \\
\hline \multirow{4}{*}{$\begin{array}{l}\text { Three- } \\
\text { planet }\end{array}$} & 1 & 630 & 4.82 & $91.4 \times 10^{3}$ & 700 & 566 & 17.2 & $82.2 \times 10^{3}$ & 2500 & 607 & 48.2 & $88.1 \times 10^{3}$ & 7000 \\
\hline & 2 & 633 & 1.41 & 91.9 & 640 & 563 & 17.2 & 81.7 & 2500 & 606 & 46.9 & 87.9 & 6800 \\
\hline & 3 & 620 & 3.86 & 90.0 & 560 & 581 & 17.2 & 84.3 & 2500 & 624 & 46.1 & 90.5 & 6700 \\
\hline & All & 628 & 7.03 & 91.1 & 1020 & 570 & 18.6 & 82.7 & 2700 & 612 & 47.5 & 88.8 & 6900 \\
\hline
\end{tabular}

\section{Planet-to-Planet Load Sharing}

The data were analyzed to determine whether or not the dynamic tooth stresses depended on which planet gear loaded the tooth. The alternating stress for each planet pass was calculated, and, by analyzing once-per-revolution signals from both the sun gear and the carrier shafts, the stress value was associated with the planet gear that loaded the tooth. The mean and standard deviations of the alternating stresses were then calculated for each planet.

Results of the analysis of data from the loaded side of the teeth are presented in Table 2. For the four-planet design, the largest mean of alternating stresses was produced by planet number three whereas the largest standard deviation is associated with planet number two. Such a definitive pattern does not exist for the threeplanet design. Analysis of data recorded at other speeds showed the same trends. The largest alternating stress and largest standard deviations occurred in the sun gear root area. The tooth root area of the thin-rimmed sun gear is loaded by sources other than the gear tooth loads. This produces a complex stress pattern and the large standard deviation.

Results of the data analysis from the unloaded side of the teeth are presented in Table 2. These tests were done by reversing both the direction of rotation and the applied torque, thereby loading what is normally the coast side of the sun and ring gears. The stresses produced on the unloaded side of the tooth are much greater than those produced on the loaded side. For the four-planet design, the standard deviations associated with planets two and four are always larger then those of planets one and three. Such a pattern does not exist for the three-planet design. Both the mean and standard deviations are greater for the four-planet design compared to the three-planet design, which indicates better planet-to-planet load sharing for the three-planet design.

To further evaluate the data to study load sharing, an index was calculated for the data in Table 2. The planet sharing index was calculated by the following relation:

$$
\text { index }=100\left(\mathrm{~A}_{\max }-\mathrm{A}_{\min }\right) / \mathrm{A}_{\mathrm{a}}
$$

where $A_{\max }$ is the mean of the alternating stress for the most heavily loaded planet; $A_{\min }$ is the mean of the alternating stress for the least heavily loaded planet; and $A_{a}$ is the mean of the alternating stress for all planets.

Table 3 lists the index for the tests done at full power. The index is always lower for the three-planet design compared to the four-planet design, indicating better load sharing.

TABLE
\begin{tabular}{|c|c|c|c|c|}
\hline $\begin{array}{c}\text { Tooth } \\
\text { side }\end{array}$ & Design & \multicolumn{3}{|c|}{ Planet sharing index } \\
\cline { 3 - 5 } & & $\begin{array}{c}\text { Ring gear } \\
\text { fillet }\end{array}$ & $\begin{array}{c}\text { Sun gear } \\
\text { fillet }\end{array}$ & $\begin{array}{c}\text { Sun gear } \\
\text { root }\end{array}$ \\
\hline \multirow{2}{*}{ Loaded } & Four-planet & 3.1 & 5.2 & 4.5 \\
& Three-planet & 2.4 & 4.0 & 3.9 \\
\hline \multirow{2}{*}{ Unloaded } & Four-planet & 13.0 & 5.8 & 6.0 \\
& Three-planet & 2.1 & 3.1 & 2.9 \\
\hline
\end{tabular}

As another way to characterize the stress patterns, the tensile stress peak data were plotted as histograms. Figures 9 and 10 illustrate the distributions of the data from the ring gear fillet gage on the loaded side of the tooth at full tested power. For both the four-planet design (Fig. 9) and the three-planet design (Fig. 10), planet number one caused the largest stress on the ring gear tooth. Analysis of data taken at other speeds showed the same trends. The data in Tables 2 and 3 and in Figs. 9 and 10 show the differences in stress caused by the individual planets. Each planet produced a slightly different load distribution. On the average, the load sharing was better for the three-planet design. No attempt was made to evaluate instantaneous load sharing or to evaluate the accuracy of the planet post locations, which is a possible factor for the different mean loads and distributions among the planets. 

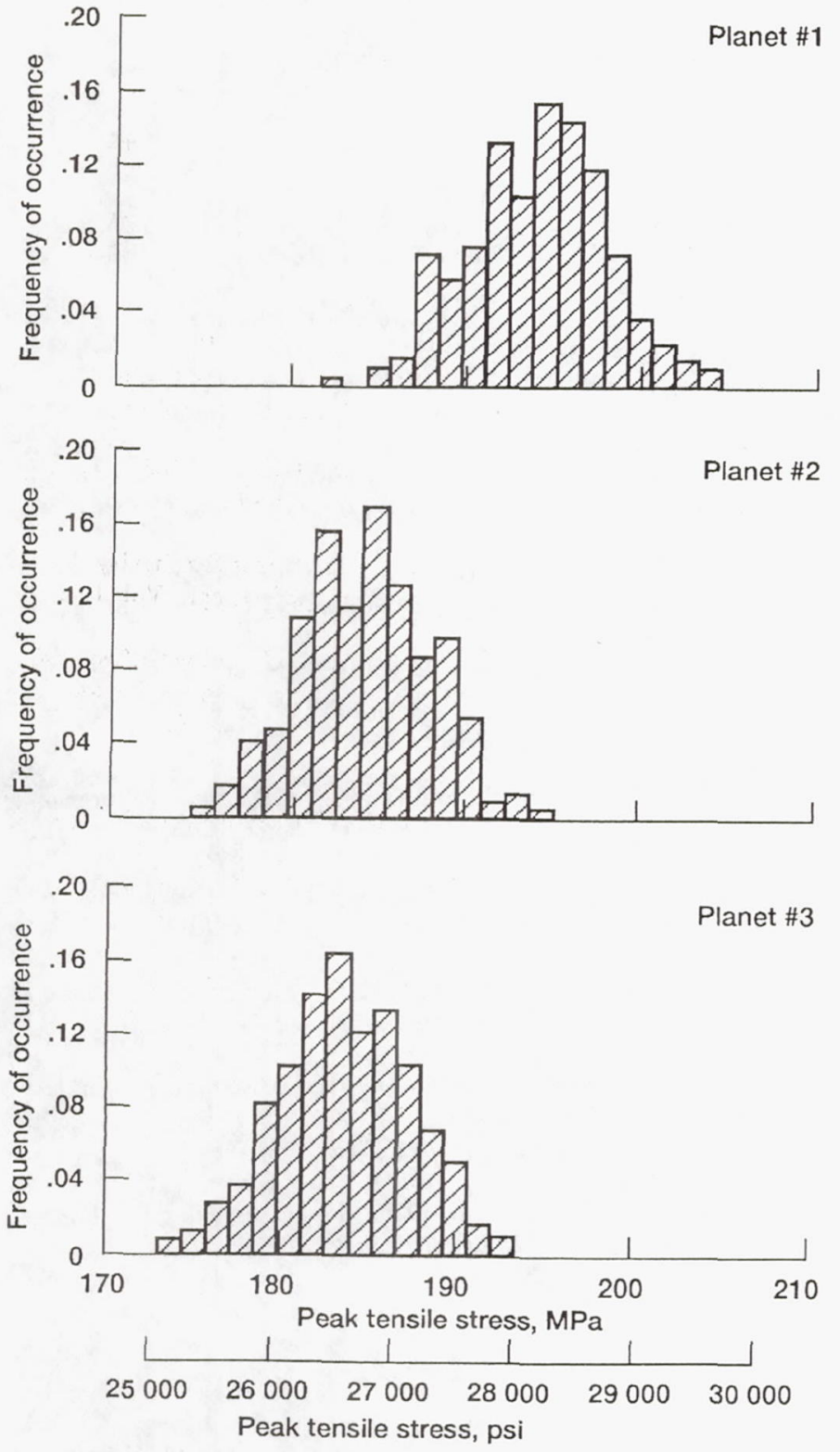

Figure 9.-Distribution of tensile peaks for three-planet design.

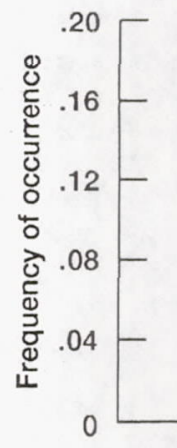

Planet \#1
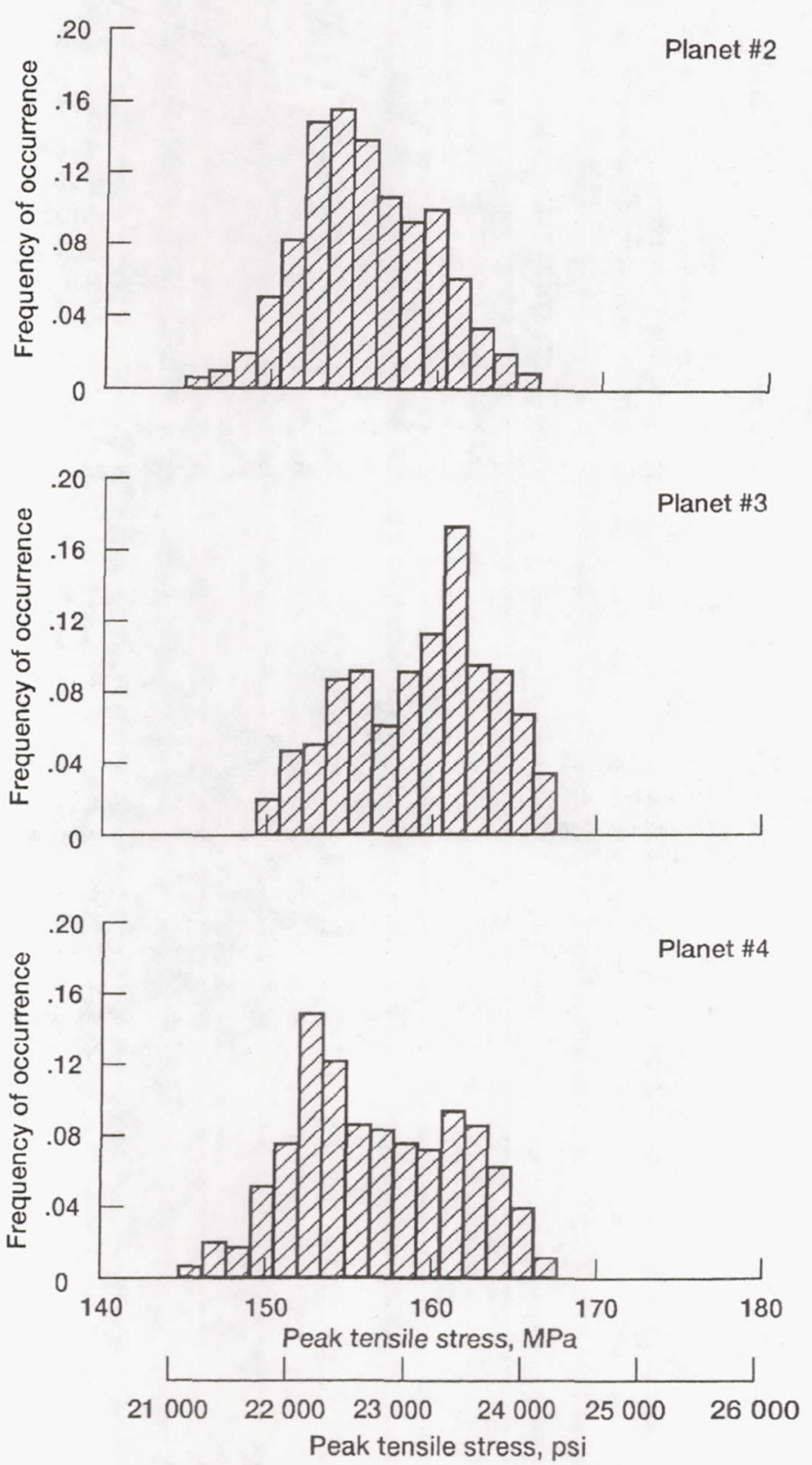

Figure 10.-Distribution of tensile peaks for four-planet design. 


\section{Trend of Results with Torque}

The alternating stresses produced by each planet were averaged together. The results of this calculation for three torques are illustrated in Fig. 11, the data for which are from the loaded side of the teeth. The response is slightly nonlinear with torque. A leastsquares quadratic fit was calculated for the data. The slope of the curve decreases slightly with increasing torque.

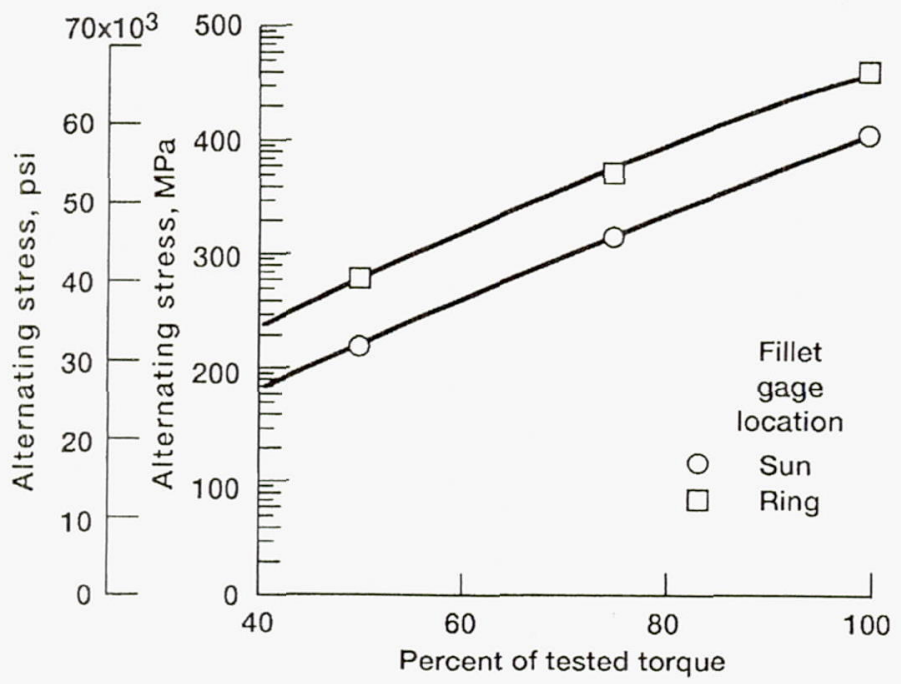

Figure 11.-Tooth stress versus sun gear torque.

\section{SUMMARY OF RESULTS}

Experiments were conducted to study the gear tooth stresses and the load sharing of two planetary reduction stages, one having three planets and the other four planets. Measurements were made using strain gages located on a ring gear tooth fillet, a sun gear tooth fillet, and a sun gear tooth root. Stresses were calculated from the measured strains and analyzed to study load sharing among the planets. The following results were obtained:

1. On the loaded side, or driving side, of the gear teeth, the alternating stress produced by a planet pass at the full tested power condition ranged from 367 to $450 \mathrm{MPa}$ (53 300 to $65300 \mathrm{psi}$ ).

2. On the unloaded side, or coast side, of the gear teeth, the alternating stress produced by a planet pass at the full tested power condition ranged from 563 to $832 \mathrm{MPa}$ (81 700 to $120700 \mathrm{psi}$ ).
3. Each planet produced its own distinctive load history on the ring and sun gears.

4. On the average, the planet-to-planet load variation for the three-planet design was about 2 to 4 percent. For the four-planet design the load variation was about 3 to 13 percent.

5 . The response of the strain gages was slightly nonlinear with torque as the response decreased with increasing torque.

6. A significant stress was produced at the tooth root location of the thin-rimmed sun gear by a phenomenon other than the passing of a planet over the neighboring teeth. It is hypothesized that a traveling wave in the thin-rimmed sun gear or a lateral vibrational mode caused these stresses at the tooth root location.

\section{REFERENCES}

Bibel, G.D., Reddy, S.K., Savage, M., and Handschuh, R.F., 1991, "Effects of Rim Thickness on Spur Gear Bending Stress," NASA TM-104388.

Botman, M., 1976, "Epicylic Gear Vibrations, Journal of Engineering for Industry," Vol. 98, No. 3, pp. 811-815.

Botman, M., 1980, "Vibration Measurements on Planetary Gears of Aircraft Turbine Engines," Journal of Aircraft, Vol. 17, No. 5 , pp. $351-357$.

Choy, F.K., Townsend, D.P., and Oswald, F.B., 1988, "Dynamic Analysis of Multimesh-Gear Helicopter Transmissions," NASA TP-2789.

Cornell, R.W., 1981, "Compliance and Stress Sensitivity of Spur Gear Gear Teeth," Journal of Mechanical Design, Vol. 103, No. 2, pp. 447-459.

Drago, R.J. and Lutthans, R.V., 1983, "Combined Effects of Rim Thickness and Pitch Diameter on Spur Gear Tooth Stresses," Journal of the American Helicopter Society, Vol. 24, No. 3, pp. 13-19.

Frater, J.L., August, R., and Oswald, F.B., 1983, "Vibration in Planetary Gear Systems With Unequal Planet Stiffness," NASA TM-83428.

Hayashi, T., et al., 1986, "Measurements and Discussions on Dynamic Load Sharing in Planetary Gears," JSME Bulletin, Vol. 29, pp. 2290-2297.

Ma, P., and Botman, M., 1984, "Load Sharing in a Planetary Gear Stage in the Presence of Gear Errors and Misalignment," ASME Paper 84-DET-54.

Oswald, F.B., 1987, "Gear Tooth Stress Measurements on the UH-60A Helicopter Transmission," NASA TP-2698.

Stockton, R.J., 1985, "Sun Gear Traveling Wave Vibration in a Sequential Planetary Gearbox," ASME Paper 85-DET-167.

Toda, A., and Botman, M., 1979, "Planet Indexing in Planetary Gears for Minimum Vibration," ASME Paper No. 79-DET-73. 
Public reporting burden for this collection of information is estimated to average 1 hour per response, including the time for reviewing instructions, searching existing data sources, gathering and maintaining the data needed, and completing and reviewing the collection of information. Send comments regarding this burden estimate or any other aspect of this Davis Highway, Suite 1204, Arlington, VA 22202-4302, and to the Office of Management and Budget, Paperwork Reduction Project (0704-0188), Washington, DC 20503.

\begin{tabular}{|l|l|l|}
\hline 1. AGENCY USE ONLY (Leave blank) & $\begin{array}{r}\text { 2. REPORT DATE } \\
\text { September } 1992\end{array}$ & $\begin{array}{r}\text { 3. REPORT TYPE AND DATES COVERED } \\
\text { Technical Memorandum }\end{array}$ \\
\hline
\end{tabular}

\section{TITLE AND SUBTITLE}

Gear Tooth Stress Measurements of Two Helicopter Planetary Stages

6. AUTHOR(S)

Timothy L. Krantz

\section{FUNDING NUMBERS}

WU-505-63-36

1L162211A47A

8. PERFORMING ORGANIZATION REPORT NUMBER

E-7015

Cleveland, Ohio 44135-3191

and

Propulsion Directorate

U.S. Army Aviation Systems Command

Cleveland, Ohio 44135-3191

9. SPONSORING/MONITORING AGENCY NAMES(S) AND ADDRESS(ES)

National Aeronautics and Space Administration

Washington, D.C. 20546-0001

and

U.S. Army Aviation Systems Command

St. Louis, Mo. 63120-1798 AGENCY REPORT NUMBER

NASA TM-105651

AVSCOM TR-91-C-038

\section{SUPPLEMENTARY NOTES}

Prepared for the Sixth International Power Tansmission and Gearing Conference, sponsored by the American Society of Mechanical Engineers, Phoenix, Arizona, September 13-16, 1992. Responsible person, Timothy L. Krantz, (216) 433-3580.

Unclassified - Unlimited

Subject Category 37

\section{ABSTRACT (Maximum 200 words)}

Two versions of the planetary reduction stages from U.S. Army OH-58 helicopter main rotor transmissions were tested at the NASA Lewis Research Center. One sequential and one nonsequential planetary were tested. Sun gear and ring gear teeth strains were measured, and stresses were calculated from the strains. The alternating stress at the fillet of both the loaded and unloaded sides of the teeth and at the root of the sun gear teeth are reported. Typical stress variations as the gear tooth moves through mesh are illustrated. At the tooth root location of the thin-rimmed sun gear, a significant stress was produced by a phenomenon other than the passing of a planet gear. The load variation among the planets was studied. Each planet produced its own distinctive load distribution on the ring and sun gears. The load variation was less for a threeplanet, nonsequential design as compared to that of a four-planet, sequential design. The results reported enhance the data base for gear stress levels and provide data for the validation of analytical methods.

\begin{tabular}{|c|c|c|c|}
\hline \multirow{2}{*}{\multicolumn{3}{|c|}{$\begin{array}{l}\text { 14. SUBJECT TERMS } \\
\text { Helicopter transmission; Gear stresses; Planetary geartrain; Load sharing }\end{array}$}} & \multirow{3}{*}{$\begin{array}{l}\text { 15. NUMBER OF PAGES } \\
10 \\
\text { 16. PRICE CODE } \\
\text { A02 } \\
\text { 20. LIMITATION OF ABSTRACT }\end{array}$} \\
\hline & & & \\
\hline $\begin{array}{l}\text { 17. SECURITY CLASSIFICATION } \\
\text { OF REPORT }\end{array}$ & $\begin{array}{l}\text { 18. SECURITY CLASSIFICATION } \\
\text { OF THIS PAGE }\end{array}$ & $\begin{array}{l}\text { 19. SECURITY CLASSIFICATION } \\
\text { OF ABSTRACT }\end{array}$ & \\
\hline Unclassified & Unclassified & Unclassified & \\
\hline NSN 7540-01-280-5500 & & & $\begin{array}{l}\text { ndard Form } 298 \text { (Rev. 2-89) } \\
\text { scribed by ANSI Std. Z39-18 } \\
-102\end{array}$ \\
\hline
\end{tabular}

